
short. "I didn't want to say, 'No, you are wrong, they aren't actually doing that well."

Instead, she said: "The story is a probably a little more complicated than what you saw on the nature documentary." That was the end of the conversation; the tourists seemed uninterested in the more-complicated story of how beavers and changes in hydrology might be more important than wolves for willow recovery. "I can't say I blame them," says Marshall, now an ecologist with the US National Oceanic and Atmospheric Administration in Seattle, Washington. "What you see on TV is captivating."

On television and in scientific journals, the story of how carnivores influence ecosystems has seized imaginations. From wolves in North America to lions

in Africa and dingoes in Australia, top predators are thought to exert tight control over the populations and behaviours of other animals, shaping the entire food web down to the vegetation through a 'trophic cascade'. This story is popular in part because it supports calls to conserve large carnivores as 'keystone species' for whole ecosystems. It also offers the promise of a robust rule within ecology, a field in which researchers have yearned for more predictive power.

But several studies in recent years have raised questions about the top-predator rule in the high-profile cases of the wolf and the dingo. That has led some scientists to suggest that the field's fascination with top predators stems not from their relative importance, but rather from society's interest in the big, the dangerous and the vulnerable. "Predators can be important," says Oswald Schmitz, an ecologist at Yale University in New Haven, Connecticut, "but they aren't a panacea."

\section{PREDATORS ON TOP}

In the early years of ecology, predators did not get so much respect. Instead, researchers thought that plants were the dominant forces in ecosystems. The theory was that photosynthesis from these primary producers determined how much energy was available in an area, and what could live there. Bottom-up control was all the rage.

Interest in top-down trophic cascades emerged in 1963, when ecologist Robert Paine of the University of Washington in Seattle started to exclude predators from study plots at his coastal research site. $\mathrm{He}$ pried predatory starfish off intertidal rocks and hurled them into deeper waters. Without the starfish to control their numbers, mussels eventually carpeted the plots and kept limpets and algae from taking hold in the region. A new ecosystem emerged (see Nature 493, 286-289; 2013).

After this and other aquatic studies, the conventional wisdom in the field was that top-down trophic cascades happened only in rivers, lakes and the sea. An influential 1992 paper $^{1}$ by Donald Strong at the University of California, Davis, asked: "Are trophic cascades all wet?" As if in answer, ecologists began looking for similar carnivore stories on land.

They soon found them. In 2000, a review ${ }^{2}$ tallied 41 terrestrial studies on trophic cascades, most of which showed that predation had significant effects on the number of herbivores in an area, or on plant damage, biomass or reproductive output. These studies were all on small plots involving small predators: birds, lizards, spiders and lots of ants.

Research on terrestrial trophic cascades moved to much larger scales with the work of John Terborgh and William Ripple. In 2001, Terborgh, an ecologist at Duke University in Durham, North Carolina, reported ${ }^{3}$ on dramatic ecosystem changes that came after a dam was built in Venezuela. Flooding from the dam created islands that were too small to support big predators such as jaguars and harpy eagles. The population densities of their prey - rodents, howler monkeys, iguanas and leaf-cutter ants boomed to 10-100 times those on the mainland. Seedlings and saplings were devastated.

In the same year, Ripple, an ecologist at Oregon State University in Corvallis, published a key paper $^{4}$ on the most famous, and probably the $\rightarrow$ NATURE.COM For a podcast on predators, visit: go.nature.com/x1npp3 best-studied, example of a terrestrial carnivore structuring an ecosystem: Yellowstone's wolves. The ecosystem offered a natural experiment because the US National Park Service had the park's exterminated wolves (Canis lupus) by 1926 and then reinstated them in the 1990s, after public sentiment and ecological theory had shifted. In 1995, 14 wolves from Alberta, Canada, were introduced into the park. Seventeen from British Columbia followed in 1996. By 2009, there were almost 100 wolves in 14 packs in the Yellowstone area. (That number is now down to 83 in 10 packs.)

During the years when there were no wolves, ecologists grew increasingly worried about the aspen trees (Populus tremuloides) in the park. It seemed that intensive browsing by Rocky Mountain elk (Cervus elaphus) was preventing trees from reaching adult height, or 'recruiting. In the early twentieth century, aspen covered between $4 \%$ and $6 \%$ of the winter range of the northern Yellowstone herd of elk; by the end of the century, they accounted for only $1 \%$ (ref. 4).

When Ripple and his co-authors checked aspen growth against the roaming behaviour of wolves in three packs, they found that aspen grew tallest in streamside spots that saw high wolf traffic. That pattern hinted at an indirect behavioural cascade: rather than limiting browsing by reducing elk populations throughout the park, wolves apparently made elk more skittish and less likely to browse in the tightly confined stream valleys, where prey have limited escape routes (see 'The tangled web'). A 2007 study ${ }^{5}$ by Ripple and Robert Beschta, also of Oregon State, seemed to strengthen the behavioural-cascade hypothesis. It found that the five tallest young aspen in stream-side stands where there were downed logs - a potential trip hazard for elk - were taller than the five tallest young aspen in stands away from streams or without downed logs.

Similar evidence of indirect wolf effects emerged from a study of willows. In 2004, Ripple and Beschta found ${ }^{6}$ that the shrubs were returning in narrow river valleys, where the researchers thought that the chances of wolves attacking elk were greatest.

More recently, Ripple has been documenting the regrowth of cottonwood trees. "When we look around western North America, we see a big decrease in tree recruitment after wolves were removed. And when wolves returned to Yellowstone, the trees started growing again. It is just wonderful to walk through that new cottonwood forest."

\section{TALES FROM TREES}

But some ecologists had their doubts. The first major study ${ }^{7}$ critical of the wolf effect appeared in 2010, led by Matthew Kauffman of the Wyoming Cooperative Fish and Wildlife Research Unit in Laramie. When researchers drilled boreholes into more than 200 trees in Yellowstone and analysed growth patterns, they found that the recruitment of aspen had not ended all at once. Some trees had reached adult size as late as 1960 , long after the wolves had gone. And some stands had stopped growing new adults as early as 1892, well before the wolves left. The aspen petered out over decades, as elk populations slowly grew, suggesting that the major influence on the trees is the size of the elk population, rather than elk behaviour in response to wolves. And although wolves influence elk numbers, many other factors play a part, says Kauffman: grizzly bears are increasingly killing elk; droughts deplete elk populations; and humans hunt elk that migrate out of the park in winter.

When Kauffman and his colleagues studied ${ }^{7}$ aspen in areas where risk of attack by wolves was high or low, they obtained results different from Ripple's. Rather than look at the five tallest aspen in each stand, as Ripple had done, they tallied the average tree height and used locations of elk kills to map the risk of wolf attacks. By these measures, they found no differences between trees in high- and low-risk areas.

Questions have also emerged about the well-publicized relationship between wolves and willows. Marshall and two colleagues investigated the controls on willow shrubs by examining ten years' worth of data 


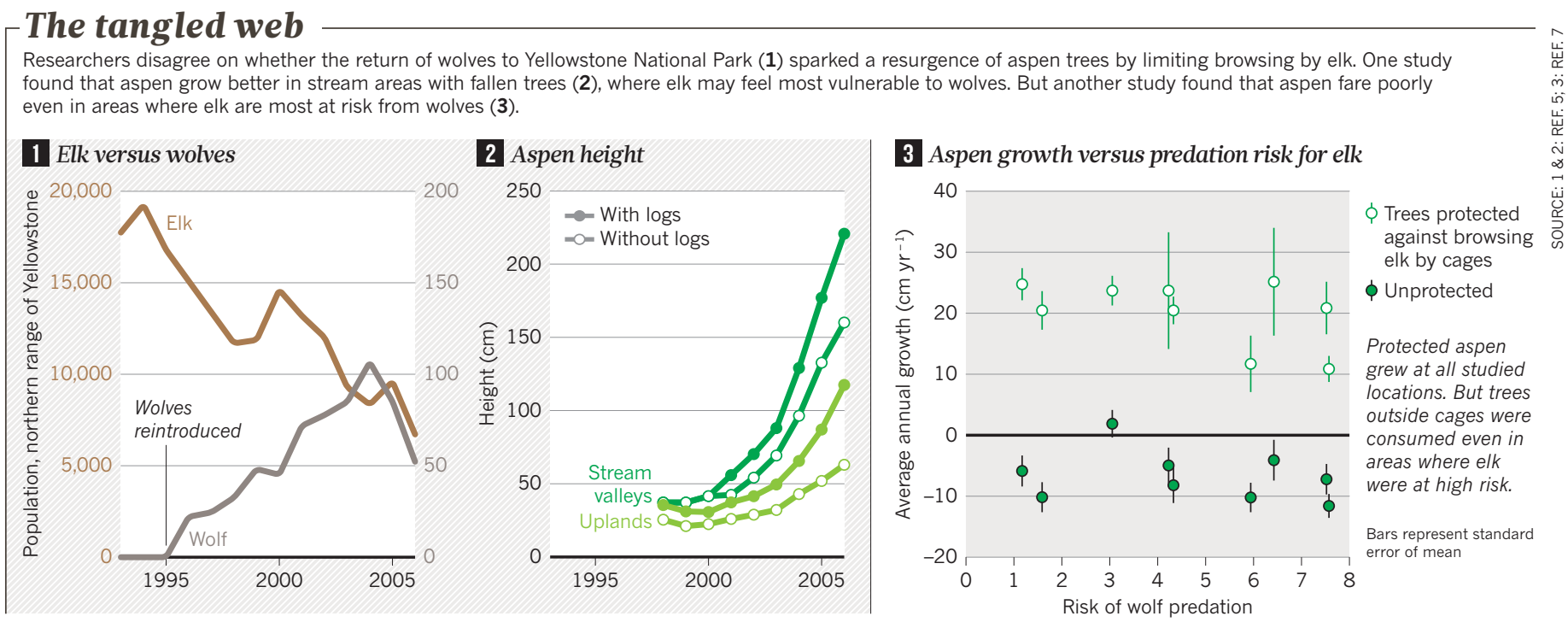

from open plots and plots surrounded by cages to keep the elk out. Her team found ${ }^{8}$ that the willows were not thriving in all the protected sites. The only plants that grew above 2 metres - beyond the reach of browsing elk - were those in areas where simulated beaver dams had raised the water table.

If beavers have a key role in helping willows to thrive, as Marshall's study suggests, the shrubs face a tough future because the park's beaver populations have dropped. Researchers speculate that the removal of wolves in the 1920s allowed elk to eat so much willow that there was none left for the beavers, causing an irreversible decline.

"The predator was gone for at least 70 years," says Marshall. "Removing it has changed the ecosystem in fundamental ways." This work suggests that wolves did meaningfully structure the Yellowstone ecosystem a century ago, but that reintroducing them cannot restore the old arrangement.

Arthur Middleton, a Yale ecologist who works on Yellowstone elk, says that such studies have disproved the simple version of the trophic cascade story. The wolves, elk and vegetation exist in an ecosystem with hundreds of other factors, many of which seem to be important, he says.

\section{DINGO DEBATE}

Another classic example of a trophic cascade has come under attack in Australia. The standard story there is that the top predator, the dingo (Canis lupus dingo), controls smaller introduced predators such as cats and foxes, allowing native marsupials to thrive. But Ben Allen, an ecologist at the Department of Agriculture, Fisheries and Forestry in Toowoomba, has compared ${ }^{9}$ areas where dingoes are poisoned with areas where they are left alone, and found no difference in marsupial abundance. He is quite cynical, he says, about "this idea that top predators are wonderful for the environment and will put everything back to the Garden of Eden".

Allen's opponents counter that he has failed to show that the poisoning regimens actually reduce dingo population densities. Chris Johnson, an ecologist the University of Tasmania in Hobart, says he is "very critical" of Allen's experimental design and methods. The dingo effect is real, says Johnson.

Ripple is not worried about these debates, which he views as quibbling over details that do not undermine the overall strength of the tropic-cascade hypothesis. In fact, when he published a major review ${ }^{10}$ this year of the effects that predators exert over ecosystems, he left out studies critical of the wolf and dingo trophic-cascade theories; he says that there was no room for them in the space he had to work with. Ripple is particularly concerned with documenting the impacts of Earth's top carnivores because so many are endangered. "We are losing these carnivores at the same time that we are learning about their ecological effects," he says. "It is alarming, and this information needs to be brought forth."
The debate has been harsh at times, but in quieter moments the different factions all tend to talk in similar terms about the great complexity of ecosystems and the likelihood that the truth lies somewhere in the middle. James Estes, an ecologist at the University of California, Santa Cruz, and one of the fathers of the trophic-cascade idea, says that the evidence for cascades mediated by changes in animal behaviour rather than by changes in animal number is "thin", at the moment - and that many of the effects that have been documented are spotty and badly need to be rigorously mapped out. Still, he adds, "When all is said and done, and everyone is dead 100 years from now, Bill [Ripple] will be closer to right".

Although Ripple stresses the role of the top carnivores, he agrees they are not the end of the story. "I believe in the combination of top-down and bottom-up, working in unison," he says. "They are both playing out on any given piece of ground and the challenge will be to discover what determines their interactions and relative effects."

Schmitz has some thoughts on how to do that. His own smaller-scale work on invertebrates has convinced him that neither bottom-up nor top-down theories adequately capture the story of ecosystems. He is starting to look at the middle players, such as elk, beavers and grasseating grasshoppers. These herbivores, he says, integrate influences from both the top (such as predation pressure) and the bottom (such as the nutritional quality of plants). "It is not really bottom-up or top-down but trophic cascades from the middle out," he says. "That is where we will evolve. It is knowing what the middle guy is going to do that gives you the predictive ability."

It remains to be seen whether theories such as this middle-out idea will grip researchers and the public as much as the theory of top-down cascades. Many researchers have doubts. They worry that tales of predators shaping their ecosystems are so attractive that they have unrivalled control over discourse. "Everyone likes to think of the big wolf or the big bear looking after the environment," says Allen. "We do love a good story." = SEE EDITORIAL P.139

\section{Emma Marris is a freelance writer in Klamath Falls, Oregon.}

1. Strong, D. R. Ecology 73, 747-754 (1992)

2. Schmitz, O. J., Hambäck, P. A. \& Beckerman, A. P. Am. Nat. 155, 141-153 (2000).

3. Terborgh, J. et al. Science 294, 1923-1926 (2001).

4. Ripple, W. J., Larsen, E. J., Renkin, R. A. \& Smith, D. W. Biol. Conserv. 102, 227-234 (2001).

5. Ripple, W. J. \& Beschta, R. L. Biol. Conserv. 138, 514-529 (2007)

6. Ripple, W. J. \& Beschta, R. L. Forest Ecol. Management 200, 161-181 (2004).

7. Kauffman, M. J., Brodie, J. F. \& Jules, E. S. Ecology 91, 2742-2755 (2010).

8. Marshall, K. N., Hobbs, N. T. \& Cooper, D. J. Proc. R. Soc. B 280, 20122977 (2013).

9. Allen, B. L. in Wolves: Biology, Behavior and Conservation (eds Maia, A. P. \& Crussi, H. F.) Ch. 3 (Nova, 2012)

10.Ripple, W. J. et al. Science 343, 1241484 (2014). 